\title{
CARDOSO, Lúcio. Chronicle of the murdered house. Tradução de Margaret Jull Costa e Robin Patterson. Rochester: Open Letter Literary Translations, 2016, 592 p.
}

Joaquim Martins Cancela Jr

Universidade Federal do Pará

Soure, Pará, Brasil

Quase sessenta anos depois de sua primeira edição pela José Olympio, em 1959, Crônica da casa assassinada, de Lúcio Cardoso é finalmente disponibilizada em língua inglesa, como anuncia enfaticamente o texto da quarta capa de Chronicle of the Murdered House, de $2016^{1}$. Três pequenos parágrafos indicam o tema da novela e fornecem alguma informação biográfica. A ilustração na capa é simples, mas potencialmente significativa: é como um tecido vinho com motivos nobres, mas que parecem rasgados pelos cantos. Se pensarmos na trama e na progressiva decadência da família Meneses, ou mesmo nos vestidos elegantes que no decorrer da narrativa são usados como símbolo de degradação tanto por Nina como por Timóteo, é possível estabelecer certa relação.

Os nomes dos tradutores, a saber, Margaret Jull Costa e Robin Patterson, aparecem já na capa, que, além do título da obra e do nome do autor, traz ainda uma citação de Benjamin Moser, classificando a narrativa como uma real revolução na Literatura Brasileira.

${ }^{1}$ CARDOSO, Lúcio. Crônica da casa assassinada. 15. ed. Rio de Janeiro: Civilização Brasileira, 2017. p. 543.

CARDOSO, Lúcio. Chronicle of the Murdered House. Tradução de Margaret Jull Costa e Robin Patterson. Rochester: Open Letter Literary Translations, 2016. p. 592. 
O livro conta com uma nota biobibliográfica também escrita por Moser e, mesmo antes disto, com uma ilustração do livro original de um mapa da propriedade dos Meneses. A imagem vem maior do que no livro original, ocupando duas páginas e suas informações, tais como "Quarto de André" ou "Fazenda Antiga" foram mantidas em Língua Portuguesa.

O conteúdo da novela é apresentado originalmente como uma reunião de diários, cartas, narrativas, confissões, depoimentos e memórias, estes organizados em sua maioria, mas não completamente, de forma cronológica. A sequência dos documentos é mantida e também não há alteração em relação aos parágrafos.

No que diz respeito à pontuação, via de regra, os travessões que indicam a fala dos personagens são substituídos por aspas, estas também utilizadas largamente para enfatizar palavras que não estavam destacadas no livro original, o que também é feito com o uso de itálico.

Sobre isto, aliás, não foi possível identificar um padrão de procedimento na tradução. Lúcio Cardoso utiliza a ênfase marcada textualmente de forma moderada, já a tradução pelo menos duplica o número de destaques. A maior parte das palavras em itálico no texto em língua inglesa está sem grifo no original, como em "You are never right, Nina" $(C M H, 59)$, no original "Você nunca tem razão, Nina" $(C C A, 64)$ e às vezes mesmo em frases inteiras e relevantes como em "The power of Evil” ( $C M H, 307)$.

A maioria dos grifos originais se mantém na tradução, como em "Onde achou isso?" (CCA, 220), "Where did you find that?" $(C M H, 238)$ e em "Nina, precisamos viver, mas agora" (CCA, 280), "We need to live, but we need to live now" (CMH, 303).

Há ainda casos mais importantes em que trechos enfatizados no original perdem seu destaque na tradução: “É que pela primeira 
vez ela me via" (CCA, 273), "For the first time, she was actually seeing me" $(C M H, 296)$, em que o itálico utilizado pelo autor marca o ponto culminante de um relevante processo de aproximação e intimidade dos personagens. Algo semelhante acontece em "que atenuante encontraria para a minha falta" $(C C A, 275)$ em inglês "what excuse could I find for my own fault" $(C M H, 298)$, em que a palavra grifada contém o elemento que talvez seja o principal de toda a narrativa: o questionamento acerca da culpabilidade na relação que André crê de natureza incestuosa.

Por último, no que diz respeito a ênfases textuais, ainda há casos curiosos como em um dos momentos mais importantes do livro em que André, transtornado, grita para Valdo o que pensa sobre um dos principais questionamentos da narrativa: a existência de vida após a morte em "PORQUE O CRISTO É MENTIRA" $(C C A, 520)$ todo escrito em maiúsculas, traduzido por "because Christ is nothing but a lie" $(C M H, 573)$ marcado em itálico. Se considerarmos que Lúcio Cardoso pouco utiliza este recurso e que, inclusive, esta é a única vez que o faz em uma frase inteira, provavelmente era porque a forma era particularmente relevante. Em geral, no entanto, a experiência de leitura do romance em língua inglesa não se altera de forma significativa pelas ênfases acrescentadas, modificadas ou omitidas na tradução.

Em relação ao uso de estrangeirismos, os procedimentos de tradução também são diversos. Como regra, os que vem do latim, sobretudo relacionados a ritos religiosos, são mantidos, tais como em "sugerindo assim que necessitava de mim in extremis" $(C C A, 183)$, "(which I took to imply that I was needed in extremis)" ( $C M H$, 197), trecho que na tradução está entre parênteses.

Há casos em que o texto traduzido introduz estrangeirismos onde não havia originalmente, como na passagem "but he had long since ceased to be a proud, magnificent grande dame" $(C M H, 231)$ sobre Timóteo, irmão dos Meneses que vivia enclausurado em seu pró- 
prio quarto, que vestia roupas femininas e é descrito como mentalmente perturbado. No original temos tão somente "mas de há muito deixara de ser a grande dama, magnífica e soberana" $(C C A, 214)$.

Ainda sobre estrangeirismos, especificamente da língua francesa, temos um caso curioso em relação à palavra toilette: em três ocorrências ela é substituída e cada uma delas de forma diferente. Na primeira "e com esse triste afã dos indiferentes, trabalhariam sua última toilette" $(C C A, 20)$, temos por tradução "and with the sad diligence of the indifferent, would dress her for the last time" $(\mathrm{CMH}$, $10)$; depois, "Que desejava ela, senão toilettes novas?" $(C C A, 364)$ é traduzido por "What could it mean other than that she wanted some new clothes?" $(C M H, 396)$; e, por fim, temos "quando ostentava toilettes que causavam a todo mundo um misto de admiração e pasmo" $(C C A, 397) \mathrm{e}$ "when she would wear outfits that provoked a mixture of shock and admiration" $(C M H, 431)$.

Passando ao campo das frases, sentiram-se livres os tradutores para, sem grandes consequências semânticas na maior parte dos casos, transmitir seu significado reescrevendo-as de outra forma, lexical e sintaticamente. Um exemplo deste procedimento está em "E eu, saindo, tive a impressão de que vira aquela mulher pela última vez $(C C A, 418)$, traduzido por "And as I left, I felt sure that I would never see that woman again" $(C M H, 457)$. Vale a pena explicitar o que mudou e que possível impacto tem no texto

Um trecho anteriormente citado, retirado da discussão entre André e Valdo também mostra isso, pois há diferenças e adições entre Porque o Cristo é mentira e Porque Cristo não é nada além de uma mentira. Até que ponto pode haver nisto algum prejuízo literário é difícil mensurar, mesmo porque o romance, em geral, parece ter como foco mais o enredo do que jogos de palavras, prevalecendo o conteúdo sobre a forma. A figuração central do romance, presente desde o título da obra, que confere à casa uma condição de organismo pelo uso do adjetivo, está contida não apenas aí como em todo 
o livro e por isso mesmo não se perde por conta de substituições vocabulares ou sintáticas uma vez que decorrem de situações, tais como a bela passagem em que a sombra da casa já deteriorada alcança Valdo à distância, em “a casa, que só por milagre ainda se mantinha de pé, projetava sobre ele a sua sombra, e parecia condená-lo, acompanhando-o até o limite onde a charrete estacara" $(C C A, 396)$ ", traduzido por "which only by a miracle remained standing and, as it cast its shadow over him, accompanying him to where the buggy had sttoped, appeared to be condemning him $(C M H, 430-431)$. Como a metáfora não reside em uma palavra, mas em uma cena inteira, não parece haver prejuízo estético neste caso, nem em tantos outros em que a residência dos Meneses e sua degradação simboliza a família tradicional mineira e seu processo de falência, esta representada pelos Meneses, descritos por Ana como feitos de cimento e cal.

Também sintaticamente há alterações, que parecem buscar adequação ao padrão Sujeito-Verbo-Objeto da língua inglesa, mais rígido que o português. Vejamos, por exemplo, o trecho "Ao regressarmos ao quarto, Dona Nina, extenuada, pediu que eu lhe arranjasse uma xícara de café" ( $C C A, 146)$, traduzido por "Dona Nina was exhausted by the time we got back to her room, and she asked me to bring her a cup of coffee" $(C M H, 156)$.

Talvez um dos poucos trechos que mereçam maior atenção a respeito deste aspecto, cuja escolha vocabular pode ter resultado em alguma perda estética, seja na passagem "devagar ele ia se despojando do seu segredo" $(C C A, 167)$ em que temos "Slowly he began to unfold his secret" $(C M H, 181)$ onde a palavra unfold não dá conta da profundidade e efeito da revelação de Alberto a Ana sobre sua vida simples e seus sentimentos por Nina.

No mais, no que concerne à carga semântica do texto, temos ainda adições de advérbios ao texto original, como em "Finally, he could hold back no longer and he spoke" $(C M H, 180)$ para "Ele não teve 
mais forças e falou" $(C C A, 167)$, em que a tradução apenas explicita textualmente uma intenção potencial original, o que ocorre como procedimento padrão ao longo do texto.

De forma geral, a leitura de Chronicles of the Murdered House confere ao leitor de língua inglesa uma experiência muito parecida à do leitor de língua portuguesa e isto se dá, em grande parte, graças à escolha estilística de Lúcio Cardoso de homogeineizar a expressão dos personagens, de forma que não há diferença linguística relevante entre a narrativa do médico, o diário de Betty, a governanta da casa, o jovem André ou mesmo as memórias de Timóteo, descrito como mentalmente desequilibrado. Todos se reportam de maneira altamente formal o que resulta na impressão de que existe, na verdade, apenas um narrador que se reveza emprestando a voz para cada um dos personagens, tanto em Crônica da casa Assassinada como em Chronicle of the Murdered House.

\section{Referências}

CARDOSO, Lúcio. Crônica da casa assassinada. 15. ed. Rio de Janeiro: Civilização Brasileira, 2017, p. 543.

CARDOSO, Lúcio. Chronicle of the Murdered House. Tradução de Margaret Jull Costa e Robin Patterson. Rochester: Open Letter Literary Translations, 2016, p. 592.

Recebido em: 19 de novembro de 2017 Aceito em: 14 de janeiro de 2018 Publicado em: maio de 2018

Joaquim Martins Cancela Jr. E-mail jmcj@ufpa.br 